\title{
Erratum to: Lack of functional $P 2 X 7$ receptor aggravates brain edema development after middle cerebral artery occlusion
}

\author{
Melanie Kaiser $^{1}$ • Anja Penk ${ }^{1}$ - Heike Franke ${ }^{1}$ • Ute Krügel $^{1}$ • Wolfgang Nörenberg ${ }^{1}$ • \\ Daniel Huster $^{2} \cdot$ Michael Schaefer $^{1}$
}

Published online: 8 November 2016

(C) Springer Science+Business Media Dordrecht 2016

Erratum to: Purinergic Signal

DOI 10.1007/s11302-016-9511-x

An error occurred while processing Fig. 2 of the above mentioned article. The NMR image, but not the ROI overlay have been mirrored. The corrected figure is shown below and is also corrected in the published version of the article.

The online version of the original article can be found at http://dx.doi. org/10.1007/s11302-016-9511-x.

Michael Schaefer

michael.schaefer@medizin.uni-leipzig.de

1 Rudolf-Boehm-Institute of Pharmacology and Toxicology, Medical Faculty, Universität Leipzig, Härtelstr. 16-18,

04107 Leipzig, Germany

2 Institute of Medical Physics and Biophysics Medical Faculty,

Universität Leipzig, Leipzig, Germany 


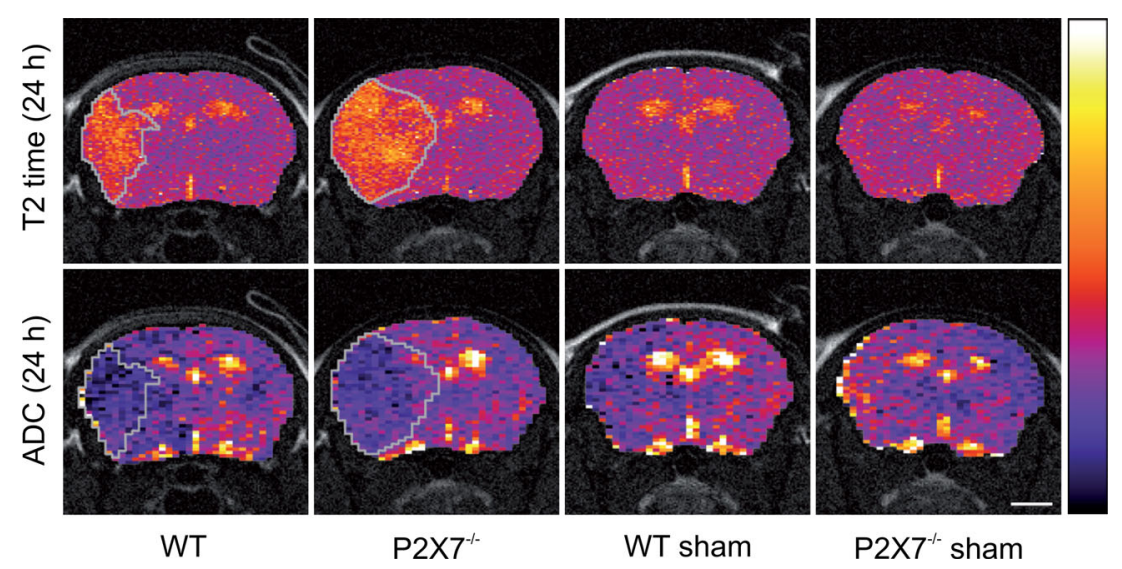

